\title{
Failure to demonstrate Babesia, Anaplasma or Ehrlichia in thrombocytopenic dogs from St Kitts
}

\author{
Patrick J Kelly, Helene Lucas \\ Ross University School of Veterinary Medicine, PO Box 334, Basseterre, St. Kitts, West Indies
}

\begin{abstract}
Background: Thrombocytopenia is common in dogs on St Kitts but there is no data on the possible etiological role played by infections with Anaplasma, Babesia and Ehrlichia, other than E. canis, which are known to occur in the Caribbean.

Methodology: Blood from 13 thrombocytopenic but apparently healthy dogs seronegative (Snap 3Dx) for E. canis were tested by PCR for Ehrlichia, Anaplasma and Babesia.

Results: All PCRs were negative.

Conclusions: The results confirm the high sensitivity of SNAP testing for E. canis and indicate Anaplasma and Babesia are not important causes of thrombocytopenia in dogs on St Kitts.
\end{abstract}

Key Words: thrombocytopenia, Ehrlichia, Anaplasma, Babesia, Caribbean

J Infect Developing Countries 2009; 3(7):561-563.

Received 16 January 2009 - Accepted 16 June 2009

Copyright $\odot 2009$ Kelly and Lucas. This is an open-access article distributed under the Creative Commons Attribution License, which permits unrestricted use, distribution, and reproduction in any medium, provided the original work is properly cited.

\section{Introduction}

Clinical experience with dogs from St Kitts indicates thrombocytopenia is a relatively common incidental laboratory abnormality and that some of these dogs respond to treatment with doxycycline, which suggests an infectious etiology. While thrombocytopenia is a very common abnormality in dogs with canine monocytic ehrlichiosis due to Ehrlichia canis, many thrombocytopenic dogs from St Kitts are negative on the Snap 3Dx assay (IDEXX Laboratories Inc., USA) used in our laboratory to diagnose such infections. The test, however, has a sensitivity of only around 71-80\% [1,2] and false negative reactions occur. In a recent report from a nearby island, Grenada, relatively high percentages of dogs were positive by PCR for E. canis (25\%), Anaplasma platys (19\%), and Babesia canis vogeli (7\%). Anaplasma platys is the agent of canine infectious cyclic thrombocytopenia and can cause low platelet counts in approximately $51 \%$ of infected dogs [3]. Similarly, about a third of dogs infected with B. canis vogeli are thrombocytopenic and $72 \%$ of dogs infected with both $A$. platys and $B$. canis vogeli had low platelet counts [3].

To determine whether thrombocytopenia in dogs seronegative for E. canis on St Kitts was due to false negative serology results for $E$. canis or infections with Babesia, Anaplasma and/or other Ehrlichia, we tested blood from thrombocytopenic dogs by PCR for infections with Babesia, Anaplasma and Ehrlichia.

\section{Methods and Materials}

In our prospective study we tested blood from 13 apparently healthy dogs that had thrombocytopenia ( $<200 \times 10^{9} / \mathrm{L}$ platelets) in full blood counts performed as a part of a routine health check in January and February of 2008. All dogs were negative for antibodies to E. canis in the Snap 3Dx assay (IDEXX Laboratories Inc., USA). The dogs were mainly male (9/13) and all but one were neutered. All were mixed breed dogs apart from one Labrador and one Australian shepherd. Ages varied between nine months and nine years, and eight dogs were recorded as being adults. Weights varied between 15 and $35 \mathrm{~kg}$ (mean $20 \mathrm{~kg}$ ). All dogs were thrombocytopenic $\left(79-164 \times 10^{9} / \mathrm{L}\right.$; mean 112$)$ but none had other abnormalities in the complete blood count results or routine serum chemistry panels (alkaline phosphatase, alanine transaminase, blood urea nitrogen, creatinine, albumin, globulins, amylase, cholesterol, calcium, phosphate, glucose, sodium, potassium and chloride).

Methods previously described by the Vector Borne Disease Diagnostic Laboratory of North Carolina State University were used for the PCR 
assays for Babesia [4] and Anaplasma and Ehrlichia $[5,6]$.

\section{Results}

The results of PCR analyses showed no dogs had DNA of Ehrlichia in their blood. Furthermore, there were no positive PCR reactions for Babesia or Anaplasma genera.

\section{Discussion}

Our finding that no samples contained DNA of Ehrlichia is consistent with the high sensitivity of the SNAP 3 Dx assay for $E$. canis reported previously $[1,2]$. This result enabled us to exclude false negative serology results for E. canis as being an important reason for undiagnosed cases of thrombocytopenia on St Kitts. Furthermore, the negative PCRs for Ehrlichia spp. indicate that other species that might infect $\operatorname{dogs}$ and cause thrombocytopenia are not present on St Kitts. These include Ehrlichia chaffeensis, the agent of human/canine monocytic ehrlichiosis; Ehrlichia ewingii, the agent of canine/human granulocytic ehrlichiosis; and Ehrlichia ruminantium, the agent of heartwater in domestic ruminants. We would note, however, that vectors of these agents (Amblyomma variegatum for E. ruminantium [8] and perhaps Rhipicephalus sanguineus for E. ewingii and E. chaffeensis [7]) are present on St Kitts and the introduction of these organisms is possible.

There were no positive PCR reactions for Babesia or Anaplasma genera despite the fact that for our study we selected dogs with thrombocytopenia, which should have increased our chances of demonstrating organisms if they were present on the island. Anaplasma platys and B. canis vogeli have, however, previously been found in Grenada [9], which shows the distribution of the organisms in the region is not uniform. Further studies are indicated to determine the distribution of these organisms among the islands. As was the case in Grenada, we could not identify Anaplasma phagocytophilum on St Kitts. It is then possible that this organism, the agent of canine/human granulocytic anaplasmosis, is not present in the region although it is found widely in the US, Europe, and Asia [10]. A probable reason for this is the fact that the vectors of A. phagocytophilum, Ixodes spp. are very uncommon in the Caribbean [8].

In summary, our results indicate infections with Babesia, Anaplasma or Ehrlichia, other than E. canis, are unlikely to be important causes of the thrombocytopenia which is seen relatively commonly in apparently healthy dogs on St Kitts. Whether these infectious agents should be considered as a cause of thrombocytopenia in dogs on other Caribbean islands, as is likely the case in Grenada [4], warrants further investigation. Similarly, there is a need to investigate other causes of thrombocytopenia in apparently healthy dogs, for example pseudothrombocytopenia, occult neoplasia, hypersplenism and drug side-effects [11].

\section{Acknowledgements}

The authors thank RUSVM for diagnostic and financial support. PCR assays for Babesia were performed at Vector Borne Disease Diagnostic Laboratory of North Carolina State University, North Carolina State University Veterinary School 4700 Hillsborough Street Raleigh, NC 27695 USA.

\section{References}

1. Bélanger M, Sorenson HL, France MK, Bowie MV, Barbe AF, Breitschwerdt EB, Alleman AR (2002) Comparison of serological detection methods for diagnosis of Ehrlichia canis infections in dogs. J Clin Microbiol 40: 3506-3508.

2. Harrus S, Alleman AR, Bark H, Mahan SM, Waner T (2002) Comparison of three enzyme-linked immunosorbant assays with the indirect immunofluorescent antibody test for the diagnosis of canine infection with Ehrlichia canis. Vet Microbiol 86: 361-368.

3. Brown GK, Canfield PJ, Dunstan RH, Roberts TK, Martin AR, Brown CS, Irving R (2006) Detection of Anaplasma platys and Babesia canis vogeli and their impact on platelet numbers in free-roaming dogs associated with remote Aboriginal communities in Australia. Aust Vet J 84: 321325.

4. Birkenheuer AJ, MG Levy, EB Breitschwerdt (2003) Development and evaluation of a seminested PCR for detection and differentiation of Babesia gibsoni (Asian genotype) and $B$. canis DNA in canine blood samples. J Clin Microbiol 41: 4172-4177.

5. Eddlestone SM, Diniz PP, Neer TM, Gaunt SD, Corstvet R, Cho D, Hosgood G, Hegarty B, Breitschwerdt EB (2007) Doxycycline clearance of experimentally induced chronic Ehrlichia canis infection in dogs. J Vet Intern Med 21:12371242.

6. Diniz PP, Schwartz DS, de Morais HS, Breitschwerdt EB (2007) Surveillance for zoonotic vector-borne infections using sick dogs from southeastern Brazil. Vector Borne Zoonotic Dis 7: 689-698.

7. Ndip LM, Ndip RN, Ndive VE, Awuh JA, Walker DH, McBride JW (2007) Ehrlichia species in Rhipicephalus sanguineus ticks in Cameroon. Vector Borne Zoonotic Dis 7: 221-227.

8. Camus E, Barre N (1995) Vector situation of tick-borne diseases in the Caribbean Islands. Vet Parasitol 57: 167-176.

9. Yabsley MJ, McKibben J, Macpherson CN, Cattan PF, Cherry NA, Hegarty, BC, Breitschwerdt EB, O'Connor T, Chandrashekar R, Paterson T, Perea ML, Ball G, Friesen S, Goedde J, Henderson B, Sylvester W (2008) Prevalence of 
Ehrlichia canis, Anaplasma platys, Babesia canis vogeli, Hepatozoon canis, Bartonella vinsonii berkhoffii, and Rickettsia spp. in dogs from Grenada. Vet Parasitol 151: 279-285.

10. Dumler JS, Choi K, Garcia-Garcia JC, Barat NS, Scorpio DG, Garyu JW (2005) Human granulocytic anaplasmosis and Anaplasma phagocytophilum. Emerg Infect Dis 11: 1828-1834.

11. Sekhon SS and Roy V (2006) Thrombocytopenia in adults: A practical approach to evaluation and management. South Med J 99: 491-498.

\section{Corresponding author}

Patrick Kelly

Ross University School of Veterinary Medicine

PO Box 334

Basseterre, St. Kitts, West Indies

Telephone: 869-465-4161

Fax: 869-465-1203

E-mail: pkelly@rossvet.edu.kn

Conflict of interest: No conflict of interest is declared. 